\title{
Robustness of a Rhythmic Circuit to Short- and Long-Term Temperature Changes
}

\author{
Lamont S. Tang, Adam L. Taylor, Anatoly Rinberg, and Eve Marder \\ Volen Center and Biology Department, Brandeis University, Waltham, Massachusetts 02454
}

Recent computational and experimental work has shown that similar network performance can result from variable sets of synaptic and intrinsic properties. Because temperature is a global perturbation that differentially influences every biological process within the nervous system, one might therefore expect that individual animals would respond differently to temperature. Nonetheless, the phase relationships of the pyloric rhythm of the stomatogastric ganglion (STG) of the crab, Cancer borealis, are remarkably invariant between 7 and $23^{\circ} \mathrm{C}$ (Tang et al., 2010). Here, we report that, when isolated STG preparations were exposed to more extreme temperature ranges, their networks became nonrhythmic, or "crashed", in a reversible fashion. Animals were acclimated for at least 3 weeks at 7, 11 , or $19^{\circ} \mathrm{C}$. When networks from the acclimated animals were perturbed by acute physiologically relevant temperature ramps $\left(11-23^{\circ} \mathrm{C}\right)$, the network frequency and phase relationships were independent of the acclimation group. At high acute temperatures $\left(>23^{\circ} \mathrm{C}\right)$, circuits from the cold-acclimated animals produced less-regular pyloric rhythms than those from warm-acclimated animals. At high acute temperatures, phase relationships between pyloric neurons were more variable from animal to animal than at moderate acute temperatures, suggesting that individual differences across animals in intrinsic circuit parameters are revealed at high temperatures. This shows that individual and variable neuronal circuits can behave similarly in normal conditions, but their behavior may diverge when confronted with extreme external perturbations.

\section{Introduction}

Nervous systems must continuously balance their need for robustness with their ability to respond to changing internal and external environments. Theoretical and experimental evidence suggests that network performance can arise from many different underlying sets of intrinsic and synaptic conductances (Prinz et al., 2004; Marder and Goaillard, 2006; Schulz et al., 2006, 2007; Goaillard et al., 2009; Norris et al., 2011; Roffman et al., 2012). However, if neural circuits across animals have different sets of underlying parameters, to what extent can animals respond in a stereotyped and robust fashion to the environmental perturbations that they are likely to encounter in their normal environments (Grashow et al., 2009; Marder, 2011)?

For the neuronal circuits of cold-blooded organisms such as fish, worms, flies, and crabs, temperature poses a considerable challenge because temperature influences the reaction rates of all cellular processes (Cossins and Bowler, 1987; Neumeister et al., 2000; Lenz et al., 2005; Zhurov and Brezina, 2005; Szabo et al.,

\footnotetext{
Received March 9, 2012; revised May 18, 2012; accepted May 24, 2012.

Author contributions: L.S.T., A.L.T., and E.M. designed research; L.S.T. and A.R. performed research; A.L.T. contributed analytic tools; L.S.T., A.L.T., and A.R. analyzed data; L.S.T., A.R., and E.M. wrote the paper.

This work was supported by National Institutes of Health Grant P01 NS044232 to M. Rosbash, Subproject 5 (E.M.). The authors declare no competing financial interests.

Correspondence should be addressed to Dr. Eve Marder, Volen Center MS 013, Brandeis University, 415 South Street, Waltham, MA 02454. E-mail: marder@brandeis.edu.

L. S. Tang's present address: Biochemistry and Biophysics, University of California, San Francisco, 1550 4th Street, Rock Hall, San Francisco, CA 94143.

A. L. Taylor's present address: Janelia Farm, 19700 Helix Drive, Ashburn, VA 20147.

DOI:10.1523/JNEUROSCI.1443-12.2012

Copyright $\odot 2012$ the authors $\quad 0270-6474 / 12 / 3210075-11 \$ 15.00 / 0$
}

2008; Dillon et al., 2009; Garrity et al., 2010; Robertson and Money, 2012), including those that govern cellular excitability and synaptic transmission (Shoemaker et al., 1990; Johnson et al., 1991; Robertson, 1993; Robertson et al., 1996; Hille, 2001; Seeger et al., 2010; Dehghani et al., 2011). One possible way to achieve appropriate circuit function over a range of temperatures is to ensure that all of the processes that govern network performance have the same temperature dependence. Because this not the case, the question remains if, and to what extent, circuit stability is maintained when cold-blooded animals face temperature changes.

Here, we study the robustness of the well characterized pyloric rhythm of the crab, Cancer borealis, stomatogastric ganglion (STG) to temperature perturbation. Temperature is an ideal global perturbation with which to challenge the robustness and reliability of the networks of cold-blooded animals, such as crabs, for several reasons. First, crabs naturally experience significant temperature fluctuations in the wild (Donahue et al., 2009). Second, temperature is a global perturbation that influences the reaction rates of all biophysical parameters (Hille, 2001). Last, while temperature influences the reaction rates of all processes, it does not influence each process equally (Robertson and Money, 2012). This last fact is particularly important when considering how network performance is maintained in response to a global perturbation such as temperature change.

We previously demonstrated that the performance of the pyloric rhythm is remarkably robust to short-term temperature changes from 7 to $23^{\circ} \mathrm{C}$ (Tang et al., 2010). We further showed that this robustness benefits from similar, but not identical, $Q_{10}$ values for several membrane currents. 
In the present work, we studied populations of animals that were acclimated for $>3$ weeks to cold $\left(7^{\circ} \mathrm{C}\right)$, medium $\left(11^{\circ} \mathrm{C}\right)$, and warm $\left(19^{\circ} \mathrm{C}\right)$ temperatures. We then determined how preparations from these populations responded to more extreme temperatures $\left(24-31^{\circ} \mathrm{C}\right)$, thus revealing whether longterm temperature history alters the behavior of the pyloric network over a range of temperature that spans physiological and extreme conditions for the crab.

\section{Materials and Methods}

Adult male C. borealis were purchased from Commercial Lobster from years 2006 to 2010 and maintained in tanks containing artificial seawater for at least 3 weeks before use. The tanks were kept at $7 \pm 1,11 \pm 1$, or $19 \pm 1{ }^{\circ} \mathrm{C}$. The complete stomatogastric nervous system (including the STG, the commissural ganglia, and the esophageal ganglion) was dissected out and pinned out in a Sylgard (Dow Corning)-coated plastic Petri dish containing chilled saline $\left(11-12^{\circ} \mathrm{C}\right)$. Physiological saline was composed of the following (in $\mathrm{mm}$ ): $440 \mathrm{NaCl}, 11 \mathrm{KCl}, 13 \mathrm{CaCl}_{2}, 26$ $\mathrm{MgCl}_{2}, 11$ Trizma base, and 5 maleic acid, $\mathrm{pH}$ 7.4-7.5.

Electrophysiology. Extracellular recordings were made by placing Vaseline wells around nerves with stainless-steel pin electrodes placed in the wells and amplified using a differential amplifier (A-M Systems). For intracellular recordings, the STG was desheathed. Intracellular recordings were obtained from cell bodies in the STG using 10-30 M $\Omega$ glass microelectrodes pulled with a Flaming/Brown micropipette puller (Sutter Instrument). The microelectrode solution contained $0.6 \mathrm{M} \mathrm{K}_{2} \mathrm{SO}_{4}$ and $20 \mathrm{~mm} \mathrm{KCl}$. The temperature of the superfusing saline was controlled using an SC-20 Peltier device and a CL-100 temperature controller (Warner Instruments). For each preparation, temperature was held constant at $7^{\circ} \mathrm{C}$ for $300 \mathrm{~s}$ and increased by increments of $4^{\circ} \mathrm{C}$ up to $31^{\circ} \mathrm{C}\left( \pm 0.5^{\circ} \mathrm{C}\right.$ variability at fixed temperature). To reduce experimental variability, each preparation was given at least $5 \mathrm{~min}$ to adapt to a new steady-state temperature before measuring rhythm output. At the end of each experiment, preparations were brought down to $11^{\circ} \mathrm{C}$. All data in this paper are from preparations that produced clearly robust pyloric rhythms when the temperature was returned to $11^{\circ} \mathrm{C}$.

Data acquisition and analysis. Data were acquired using a Digidata 1200 data acquisition board (Molecular Devices) and analyzed using Clampfit 9.0 (Molecular Devices), Spike 6.0 (Cambridge Electronic Design), MATLAB (MathWorks), and SigmaPlot (SPSS, Inc.). Average burst-to-burst pyloric dilator (PD) onset time was used to quantify network frequency. Phase was measured as the time to burst onset/offset for each cell from PD onset, normalized by the cycle period. Temperature sensitivity was quantified using $Q_{10}$. A temperature-dependent quantity (e.g., frequency) was fit to the following equation: $R(T)=R_{0} Q_{10}^{\left(T-T_{0}\right) / 10}$, where $R$ is the value of the quantity at temperature $T$, $R_{0}$ is the value at the reference temperature, $Q_{10}$ describes the temperature sensitivity, and $T_{0}$ is the reference temperature. To find values for $Q_{10}$, data were log-transformed and fit with a line.

Quantification of robustness. We created a "robustness index" (RI) to quantify the relative regularity of the pyloric rhythm at different temperatures. For these calculations, we used $295 \mathrm{~s}$ extracellular recordings of the pyloric dilator nerve (pdn), the gastropyloric nerve (gpn), and the pyloric nerve (pyn) that were first converted to PD, lateral pyloric (LP), and pyloric (PY) spike trains. The analysis consisted of three main steps, done on each spike train independently: (1) determination of the dominant frequency, (2) breaking the recordings up into short windows, and (3) performing an $F$ test to characterize the spectral peaks.

Step 1. Although the pyloric rhythm can be quite irregular at high acute temperature, there is usually a discernable periodicity to it, reflected in a "bump" in the power spectrum between 0.5 and $6 \mathrm{~Hz}$. We call this the "dominant frequency." (For robust rhythms, the dominant frequency was equal to the pyloric frequency.) For later analysis, it is useful to rescale the time axis so that this peak occurs at $f=1$ in the rescaled units. We determined the dominant frequency by calculating the power spectrum of the full $295 \mathrm{~s}$ trace, smoothing it, and automatically locating the peak between 0.5 and $6 \mathrm{~Hz}$. We verified that this peak was consistent with any periodicity apparent in the spike trains. In 15 trials (of 172 presented here), automatic identification of the dominant frequency failed to give a plausible result, so we determined the dominant frequency by examining the power spectrum manually. Power spectra were calculated using Thompson's direct multitaper method, with six windows, a timebandwidth product equal to 4 , and seven tapers, resulting in a frequency resolution of $0.081 \mathrm{~Hz}$ (Percival and Walden, 1993). Smoothing was done by convolving this spectrum with a Gaussian having SD equal to the frequency resolution.

Step 2. We wanted a measure that could be applied to short windows of data (1.5-15 s) because at higher temperatures the rhythms were often not stationary. We therefore rescaled the time base of each recording to put the dominant frequency at $f=1$ in the rescaled units and chopped up the rescaled spike train into windows with a duration of 5 units. (For a robust rhythm, this would correspond to five cycles.)

Step 3. For each window, we then calculated the robustness index by detecting spectral "lines" (i.e., sharp peaks corresponding to a truly periodic component) in the power spectrum of each spike train (Percival and Walden, 1993). This produces an estimate of the amplitude of any such periodic component as a function of frequency, and a $p$ value (based on an $F$ statistic) at each frequency. This $p$ value is small if that frequency is likely to contain a spectral line. We found the maximum amplitude between rescaled frequencies of $1 / 2$ and 2 , and based the robustness index on the $p$ value at that frequency. These $p$ values are being computed at many frequencies, however, so we applied a Sidak correction, where the number of comparisons is equal to the number of samples used to calculate the spectrum $(N)$. This gives a corrected $p$ value of $p=1-\left(1-p_{\text {raw }}\right)^{N}$, where $p_{\text {raw }}$ is original $p$ value.

We wanted the robustness index to be higher for more regular rhythms, so our robustness index, RI, is given by the following: RI = $1-$ $p=\left(1-p_{\text {raw }}\right)^{N}$. Thus, the RI is always between 0 and 1 , and RIs near 1 correspond to very robust rhythms, with RIs near 0 corresponding to the complete lack of a rhythm.

While in many situations it is desirable to have the RI bounded by 0 and 1 , in some cases this is inconvenient, because it implies that RIs near 1 (or 0 ) are unlikely to have a normal distribution. Therefore, in some cases, we subjected the RI to a log-odds transform and use the log-odds RI (LORI) as follows:

$$
\text { LORI }=\ln \frac{1-p}{p}=\ln \frac{\left(1-p_{\text {raw }}\right)^{N}}{1-\left(1-p_{\text {raw }}\right)^{N}} .
$$

The log-odds transform is commonly used in statistics to convert a quantity on the interval $(0,1)$ to one that spans all possible real values, and is more likely to be normally distributed, or at least not to deviate as badly from normality. Note that the log-odds transformation is monotonic: if the RI of one preparation is larger than another, then the LORI will be larger also. A corrected $p$ value of 0.05 corresponds to a per-window LORI of $\sim 3$, with smaller $p$ values giving larger LORI scores. To calculate the overall LORI for the full $295 \mathrm{~s}$ record, we averaged all the per-window LORIs. This measure corresponds well to what inspection of the raw traces show: rhythms judged by eye to be more robust are very likely to have a higher RI, and therefore a higher LORI.

Quantification of phase for irregular rhythms. In addition to quantifying the robustness of the pyloric rhythm, we also quantified the variation in the phase relationships between the three pyloric cell types. Because this method had to work even when the pyloric rhythm was not robust, the method had to be independent of traditional measures that use detection of burst onset and offset. Consequently, we computed the coherence between spike trains to quantify phase relationships (Thomson and Chave, 1991; Percival and Walden, 1993; Rehm et al., 2008). Coherence is a spectral analog of the correlation coefficient. It is a complex quantity, with both a magnitude and a phase, and is a function of frequency; the magnitude is $\leq 1$. To calculate coherence between pairs of spike trains at the dominant frequency, we used Thomson's direct multitaper method, with the same 295 s stretch of data used above, and the same time-bandwidth product and number of tapers. 
A

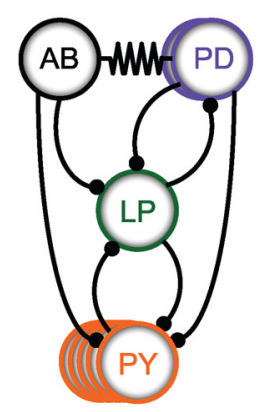

B
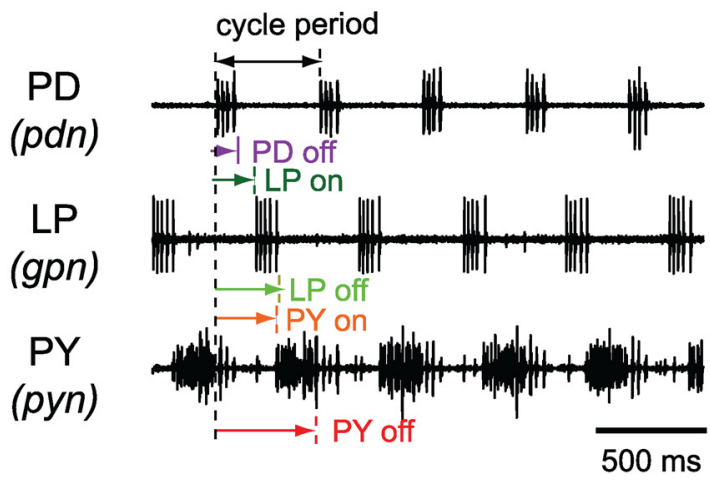

C

- $\mathrm{T}=7^{\circ} \mathrm{C}$ acclimated

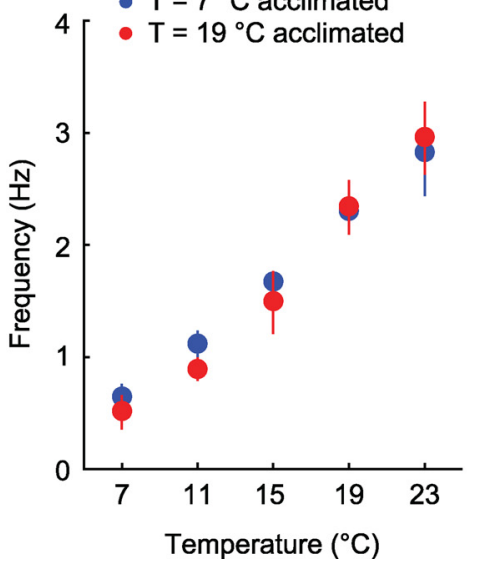

$\mathrm{D}$

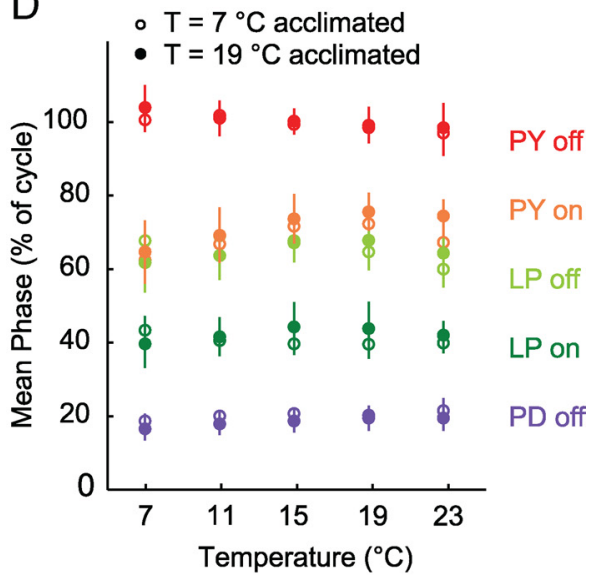

Figure 1. Quantification of pyloric network output for cold- and warm-acclimated animals at different acute temperatures. $A$, Connectivity diagram of the pyloric network containing the AB/PD, LP, and PY neurons. Resistor symbol signifies electrical coupling, and the black dots represent inhibitory synaptic connections. $\boldsymbol{B}$, Example simultaneous extracellular nerve recordings of a robust pyloric rhythm at $19^{\circ} \mathrm{C}$. The onset and offset delay of each neuron relative to the $\mathrm{PD}$ neuron are indicated. Note that in this example, PY burst is followed by spikes of another neuron, most clearly seen in third and fifth bursts. $C$, The pyloric network frequency of warm-acclimated $\left(19^{\circ} \mathrm{C} ; n=12\right)$ and cold-acclimated $\left(7^{\circ} \mathrm{C} ; n=11\right)$ animals plotted as a function of acute temperature. $\boldsymbol{D}$, Mean phase (over many cycles) of pyloric cell onset and offset for the two acclimation groups plotted as a function of acute temperature. Error bars in $\mathbf{C}$ and $\boldsymbol{D}$ indicate SD.

To test the statistical significance of the variability in coherence as acute temperature was varied, we used Levene's $s$ test, in which each complex coherence was treated as a vector. For each acute temperature, the vector mean was calculated. The distance of each coherence from this mean was then squared, and the resulting values were used as surrogate data in a one-way ANOVA (Levene, 1960; Miller and Brown, 1997).

\section{Results}

The pyloric network of the STG generates rhythmic stomach movements that are important for the animal to digest food (Marder and Bucher, 2007). The pyloric circuit consists of a three-neuron pacemaker ensemble [the single anterior burster $(\mathrm{AB})$ and two PD neurons], and the follower neurons, the LP, and the PY neurons (Fig. $1 A$, schematic connectivity diagram). The $\mathrm{PD}, \mathrm{LP}$, and PY neurons are active in a repeating triphasic motor pattern, in which the PD, LP, and PY neurons fire in alternation. This is seen in the extracellular recordings of the motor nerves from the STG (Fig. $1 B$ ). The activity of the PD neurons is seen on the pdn, the gpn carries the axon of the LP neuron, and the pyn shows the axons of the PY neurons.

By convention, the onset of the PD neuron burst is designated as the beginning of the pyloric rhythm cycle, and the onset/offset times of all other neurons are measured in reference to the PD neuron onset. One cycle period is defined as the time between the onset of one PD burst and the onset of the

subsequent PD burst (Fig. 1B). The phase onset/offset of each neuron is defined as the delay to the onset/offset of each neuron divided by the cycle period.

\section{Temperature acclimation of the} pyloric rhythm

We previously studied the effects of temperature on animals that were held at $11^{\circ} \mathrm{C}$ and found that increases in temperature increased the frequency of the pyloric rhythm with a $Q_{10}$ of $2.3 \pm 0.2(\mathrm{SD})$, but the phase relationships were temperature invariant (Tang et al., 2010). We wondered whether acclimation of animals to different temperatures would change their responses to acute temperature changes. Therefore, we acclimated all of the animals in this study to temperatures of $7^{\circ} \mathrm{C}(n=11), 11^{\circ} \mathrm{C}(n=9)$, or $19^{\circ} \mathrm{C}$ $(n=12)$ for at least 3 weeks. These are temperatures well within the range that $C$. borealis experience in nature (Donahue et al., 2009). (For brevity, below we refer to these groups as cold-, mid-, and warmacclimated, respectively.)

The responses of the cold- and warmacclimated animals to acute temperature swings are shown in Figure 1, $C$ and $D$. Within the "permissive" temperature range from 7 to $23^{\circ} \mathrm{C}$, cold- and warmacclimated animals responded similarly to each other, and to mid-acclimated animals (Tang et al., 2010). The pyloric rhythm frequency in the cold-acclimated animals increased approximately fourfold over this temperature range, from $0.73 \pm$ 0.11 to $2.79 \pm 0.34(\mathrm{SD}) \mathrm{Hz}$, with a $Q_{10}$ of $2.31 \pm 0.30(\mathrm{SD})$. For the warm-acclimated animals, the frequency also increased approximately fourfold, from $0.63 \pm 0.13$ to $3.03 \pm 0.33 \mathrm{~Hz}$, with a $Q_{10}$ of $2.78 \pm$ 0.24 . There were no significant differences in either the slope or $y$-intercept of the temperature dependence (when plotted on a log scale) between acclimation groups $(p=0.11$ and $p=0.46$, respectively, one-way ANCOVA; Fig. 1C). Mid-acclimated animals showed a $Q_{10}$ of $2.32 \pm 0.20$ for the pyloric frequency (Tang et al., 2010) and also showed no statistical difference from the other two acclimation groups.

Previous work on animals acclimated to $11^{\circ} \mathrm{C}$ showed that the phase relationships of the pyloric rhythm neurons were remarkably temperature invariant, meaning that all the onset and offset phases of each individual neuron exhibited $Q_{10}$ values approximately equal to 1 (Tang et al., 2010). Within the permissive temperature range, both the cold- and warm-acclimated animals also exhibited excellent temperature invariance of phase (Fig. 1D). Statistical significance across the acclimation groups was found for temperature dependence of LP onset and LP offset slopes ( $p<0.05$ and $p<0.01$, one way ANCOVA, respectively), as well as for the $y$-intercept of the temperature dependence of the PD offset ( $p<0.001$, one way ANCOVA). These differences, while reaching statistical significance, were small and may not be functionally important for the animal. For all other values, no statis- 


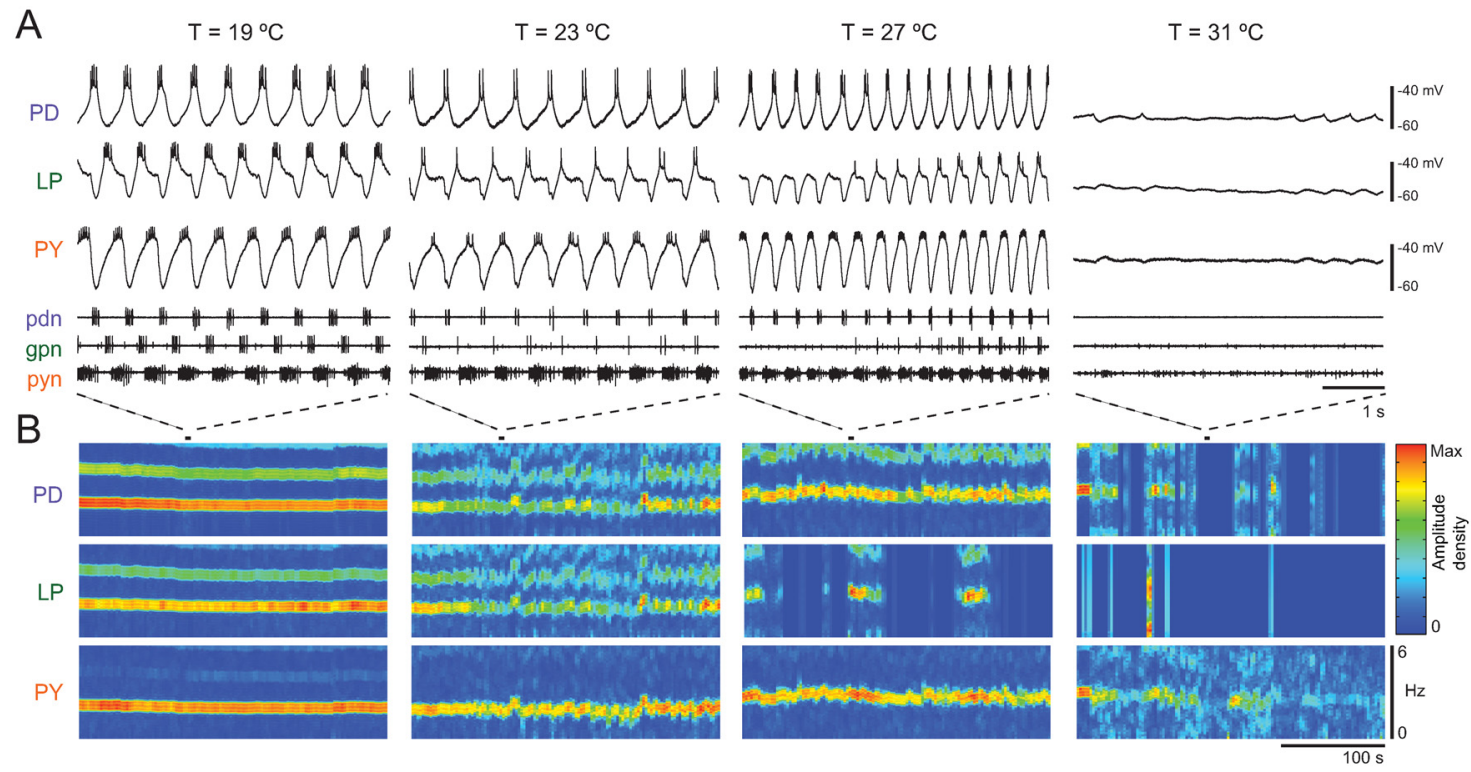

Figure 2. An example of a cold-acclimated animal transitioning from robust circuit performance to a crash as temperature is increased past the normal operating range of the circuit. $\boldsymbol{A}$, Simultaneous, intracellular recordings of the PD, LP, and PY neurons (top three traces) and their associated extracellular nerve recordings (pdn, gpn, and pyn, respectively; bottom three traces) revealing the different patterns of activity at different acute, steady-state temperatures. The circuit progresses from a robust, bursting rhythm at a permissive temperature $\left(19^{\circ} \mathrm{C}\right)$, to a sporadically spiking rhythm with steady underlying slow waves $\left(23-27^{\circ} \mathrm{C}\right)$, and finally to a completely crashed rhythm with no underlying slow wave oscillations $\left(31^{\circ} \mathrm{C}\right)$. The two dashed lines below the extracellular traces indicate the point in time from which these selected traces were obtained. $B$, Spectrograms of the PD, LP, and PY neurons revealing the different types of activity (from left to right panels: robust, weak, intermittent, and complete crash) over a $300 \mathrm{~s}$ recording. Each spectrogram was obtained from the same individual and the same temperatures as in $\boldsymbol{A}$. The color scale is normalized to the maximum amplitude density of each preparation (see Materials and Methods).

tical differences were found for slope and $y$-intercept across the two acclimation groups.

\section{More extreme temperatures disrupt the pyloric rhythm}

While functional circuit performance is robust for acute temperatures within the permissive range, at extreme temperatures one might expect that circuit performance will be disrupted due to different circuit component temperature sensitivities. Because each underlying circuit parameter may exhibit a different $Q_{10}$, it becomes more likely that the underlying circuit parameters will become incompatible as temperature is increased. We investigated this by increasing the acute temperature to the point at which the pyloric rhythm failed.

Although there were some individual preparations that generated robust triphasic pyloric rhythms up to $31^{\circ} \mathrm{C}$, in general, the robustness of the pyloric circuit decreased after some critical temperature, particular to each animal. Figure $2 A$ shows simultaneous intracellular recordings from the PD, LP, and PY (top three traces) and the corresponding extracellular recordings from the pdn, gpn, and pyn nerves (bottom three traces) in a single preparation, at temperatures from 19 to $31^{\circ} \mathrm{C}$. At $19^{\circ} \mathrm{C}$ (Fig. $2 \mathrm{~A}$, first column), PD, LP, and PY sequentially and robustly fired bursts of action potentials in a reliable triphasic pyloric rhythm. At $23^{\circ} \mathrm{C}$ (Fig. $2 \mathrm{~A}$, second column), some burst cycles showed some missing action potentials, but the underlying slow membrane potential oscillation remained robust. As the temperature was further increased to $27^{\circ} \mathrm{C}$ (Fig. $2 \mathrm{~A}$, third column), there were stretches of time during which the LP neuron failed to fire, alternating with stretches of time during which the LP fired robustly. During all stretches, the PD and PY neurons were strongly active. At $31^{\circ} \mathrm{C}$ (Fig. 2A, last column), the pyloric rhythm "crashed" (stopped oscillating) altogether.

The traces of disrupted rhythms at the high temperature demonstrate why traditional burst detection cannot capture these irregular patterns of activity over long stretches of time. For these reasons, we used spectral techniques (Fig. $2 B$ ) to analyze circuit performance at extreme temperatures. We analyzed $300 \mathrm{~s}$ spans of spiking behavior and analyzed the burst frequency and spectral power of each individual neuron as a function of temperature. Figure $2 B$ shows the spectrograms corresponding to the spike traces from Figure $2 \mathrm{~A}$. At $19^{\circ} \mathrm{C}$ (Fig. $2 \mathrm{~B}$, first panel), the spectrograms of the PD, LP, and PY neurons show high power at the pyloric frequency $(\sim 2 \mathrm{~Hz}$; top, middle, and bottom spectrograms). A narrow red band indicates stable, periodic bursting, while a spread-out or fluctuating signal corresponds to weak, irregular bursting. Furthermore, the rhythmic activity was stable over time, as the power remained constant along the band for all three neurons. At $23^{\circ} \mathrm{C}$ (Fig. $2 \mathrm{~B}$, second panel), the power in the pyloric band was still present for all three neurons, but the power was noticeably weaker in the PD and LP neuron, and thus reflects a modest degradation in the robustness of the pyloric rhythm. At $27^{\circ} \mathrm{C}$ (Fig. $2 \mathrm{~B}$, third panel), the pyloric band was still present for the PD and PY neurons, but the LP neuron was completely lacking power in all frequencies for most of the record. The exceptions to these long stretches of silent activity were the small stretches of robust triphasic activity from $\sim 0$ to 25,100 to 135 , and 205 to 235 s. Finally, at $31^{\circ} \mathrm{C}$ (Fig. $2 \mathrm{~B}$, last panel), the spectrograms of the PD, LP, and PY neurons show relatively little power in the pyloric band, reflecting long periods of time in which the PD, LP, and PY neurons were silent (Fig. $2 A$ ).

\section{Variability of activity patterns at high temperature}

The robustness of circuit performance as a function of temperature varied within an individual, across individuals, and across acclimation groups. Several qualitatively different types of circuit failures were seen at extreme temperature ranges, some of which are displayed in Figure 3. At the boundaries between the permissive and nonpermissive temperature range, robust patterns of 
A Robust network activity intterupted by intermittent crashes

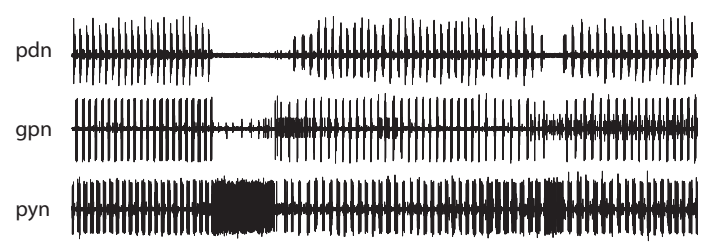
C

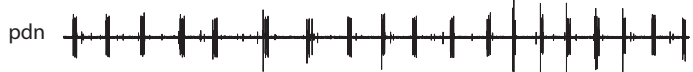
gpn pyn

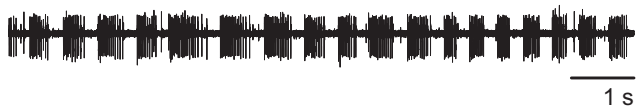

B

Irregular bouting

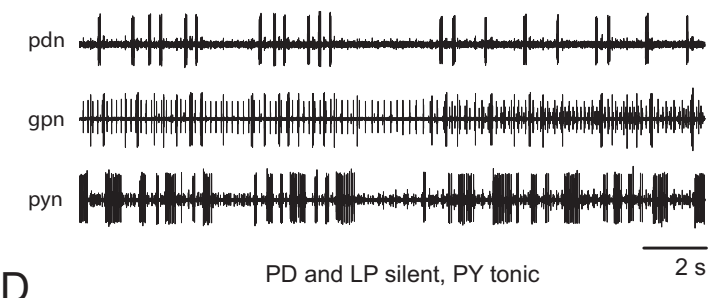

pdn

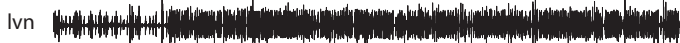

pyn

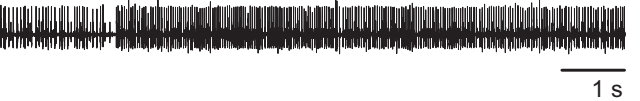

Figure 3. Examples of nonrobust pyloric motor patterns at extreme temperatures $\left(>23^{\circ} \mathrm{C}\right)$. For $\boldsymbol{A}-\boldsymbol{D}, \mathrm{PD}, \mathrm{LP}$, and PY neuron activity obtained from simultaneous extracellular recordings exclusively (pdn, gpn/lvn, and pyn; top, middle, and bottom traces, respectively). $\boldsymbol{A}$, An example of a robust pattern of activity that is interrupted intermittently by nonrobust activity in which PD and $\mathrm{LP}$ are silent but $\mathrm{PY}$ is tonic (recorded at $27^{\circ} \mathrm{C}$; animal acclimated at $\left.7^{\circ} \mathrm{C}\right) . \boldsymbol{B}$, An example of irregular patterns of activity that resemble the bouting behavior that is observed in decentralized stomatogastric nervous systems (recorded at $27^{\circ} \mathrm{C}$; animal acclimated at $7^{\circ} \mathrm{C}$ ). $C$, An example of a semirobust pattern of activity in which the PD and PY neurons exhibit regular bursting behavior, but the $L P$ neuron is relatively quiet (recorded at $27^{\circ} \mathrm{C}$; animal acclimated at $\left.7^{\circ} \mathrm{C}\right)$. $\boldsymbol{D}$, An example of PD and LP neuron becoming silent, but PY becoming tonic ( $L P$ spikes are the largest ones on Ivn, only two LP spikes are seen in this Ivn trace; recorded at $27^{\circ} \mathrm{C}$; animal acclimated at $\left.7^{\circ} \mathrm{C}\right)$.

network activity were sometimes interrupted by intermittent failures in one or more neurons (Fig. $3 A$ ). In some cases, the pyloric circuit would devolve into irregular patterns of activity that resembled the "bouting" behavior seen in STG preparations recovering from loss of modulatory inputs (Luther et al., 2003) (Fig. 3B). In other preparations, two of the neurons would appear to be bursting in pyloric time, but another neuron would either be relatively quiet or out of phase (Fig. 3C). In other cases, two of the neurons would be relatively quiet and the other neuron would fire tonically (Fig. 3D).

\section{Effects of extreme temperature on circuit robustness}

Spectrograms allow us to study rhythm stability over long timescales at different temperatures and qualitatively compare across acclimation groups. To illustrate the kinds of crashes that occur, Figure 4 shows the spectrograms of the PD, LP, and PY neurons from nine different animals as a function of increasing temperature. Figure $4 A-E$ shows representative spectrograms from cold-acclimated animals, and Figure $4 F-I$ shows representative spectrograms from warm-acclimated animals. With the exception of Figure $4 E$ at $23^{\circ} \mathrm{C}$, the spectrograms of the PD, LP, and PY neurons from 15 to $23^{\circ} \mathrm{C}$ show that all of the preparations generated typical and robust pyloric rhythms. The 7 and $11^{\circ} \mathrm{C}$ spectrograms, while not shown, also displayed robust pyloric rhythms.

For cold-acclimated animals, several interesting features emerged at high acute temperatures. At $27^{\circ} \mathrm{C}$, the preparations seen in Figure $4, A$ and $B$, were both characterized by continuous power in the pyloric frequency band for the entire $300 \mathrm{~s}$ record. At $31^{\circ} \mathrm{C}$, the amplitude was intermittent (i.e., short stretches of robust pyloric activity alternated with short stretches of weak pyloric activity). In another preparation (Fig. 4C), weak and fluctuating $\mathrm{PD}$ and $\mathrm{PY}$ activity at $31^{\circ} \mathrm{C}$ were accompanied by almost no power from the LP neuron. In contrast, a fourth preparation (Fig. 4D) displayed relatively strong, but unstable power (i.e., a gradual decrease in the frequency disrupted by a short increase in frequency and subsequently followed by another gradual decrease in frequency) in the three neurons at $27^{\circ} \mathrm{C}$ for the entire 300 s recording session with the exception of a slight "hiccup" in which all three neurons were silent for $\sim 10 \mathrm{~s}$. As temperature was further increased to $31^{\circ} \mathrm{C}$, the power became diffuse in all three neurons. Last, Figure $4 E$ shows a preparation that lost almost all rhythm stability at $27^{\circ} \mathrm{C}$. Even at $23^{\circ} \mathrm{C}$, this network experienced sputters of rhythm breakdown.

In contrast to the cold-acclimated animals, most of the animals from the warm-acclimated group appeared to maintain robust circuit performance at $27^{\circ} \mathrm{C}$ (Fig. $4 F-I$ ). In general, the spectrograms from the warm-acclimated group at this temperature showed relatively strong and stable power at the pyloric frequency band, with some fluctuations in the frequency. As the temperature was increased to $31^{\circ} \mathrm{C}$, the power in the pyloric band became weaker (Fig. $4 F, G$ ), and in some cases the frequency became more variable (Fig. $4 H, I$ ). There were few preparations in which the rhythm was lost entirely for a prolonged period of time.

\section{Reversibility, stability, and reproducibility of crashes}

One potential explanation for the failures in network performance at high temperatures is irreversible neuronal heat damage. To determine whether this was the case, we repeatedly heated and cooled individual preparations from a permissive temperature to a crash-inducing temperature. An example of this is shown in Figure 5. At $23^{\circ} \mathrm{C}$ (Fig. 5, first column), the PD, LP, and PY neurons were in typical pyloric time. However, when the temperature was raised to $31^{\circ} \mathrm{C}$, the preparation crashed. This was reflected in the lack of power in the PD, LP, and PY neuron spectrograms, with the exception of two short 10-20 s episodes of robust activity spaced $\sim 150 \mathrm{~s}$ apart from one another (Fig. 5, second column). When the temperature was returned to $27^{\circ} \mathrm{C}$, the PD, LP, and PY neurons resumed their robust pattern of activity (Fig. 5, third column). Finally, when the temperature was increased again to $31^{\circ} \mathrm{C}$, the resulting crash was remarkably similar to that seen in the previous exposure of the preparation to $31^{\circ} \mathrm{C}$ (Fig. 5, fourth column).

To quantitatively evaluate functional circuit operation at different temperatures, we devised the RI, which quantifies the robustness of rhythmic activity in each individual neuron (see Materials and Methods). Figure 5 shows a number of spectrograms with their associated RI traces. As can be seen, RI values near 1 indicate robust pyloric-timed activity, while values near 0 indicate activity with little rhythmicity. 
Cold-acclimated animals

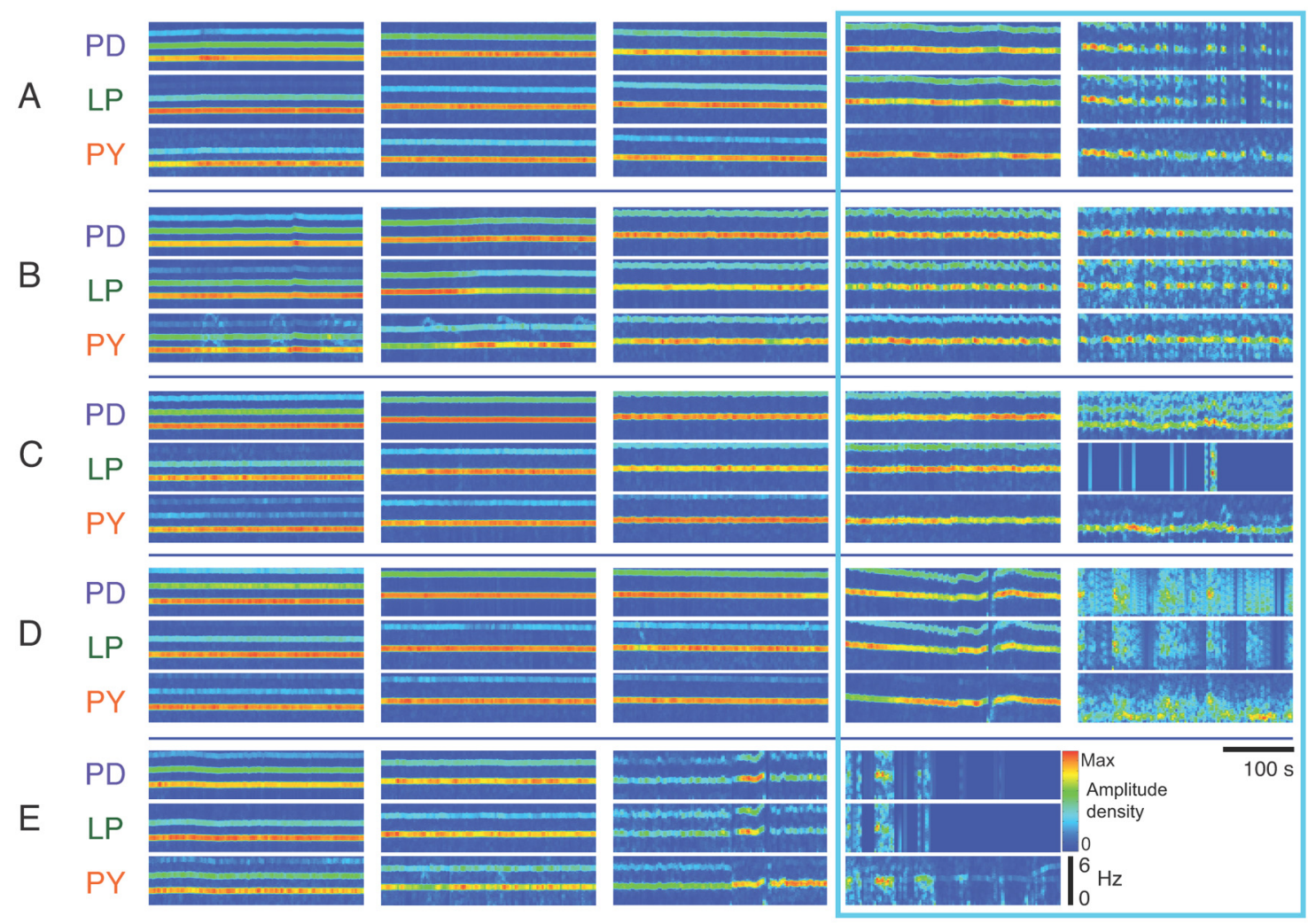

Warm-acclimated animals

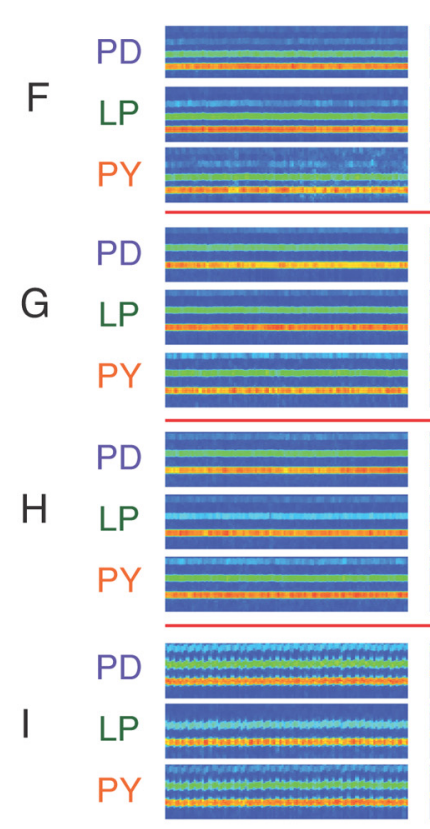

$15^{\circ} \mathrm{C}$
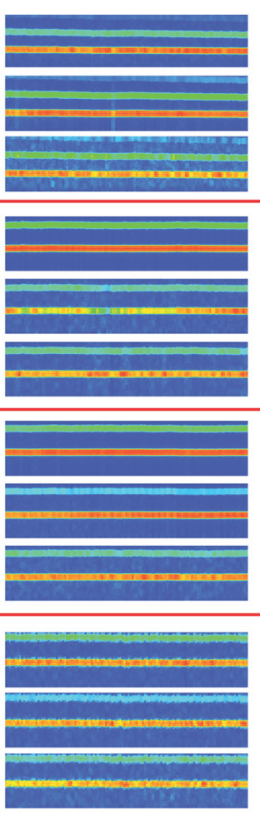

$19^{\circ} \mathrm{C}$

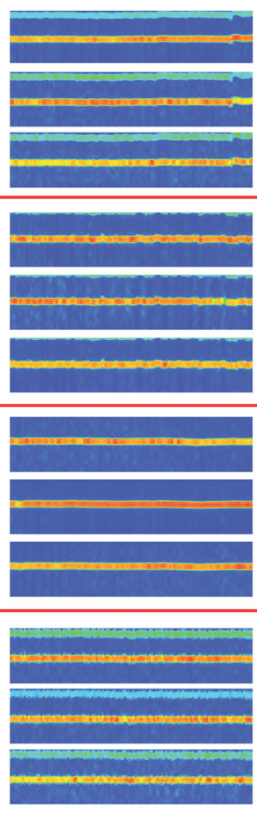

$23^{\circ} \mathrm{C}$

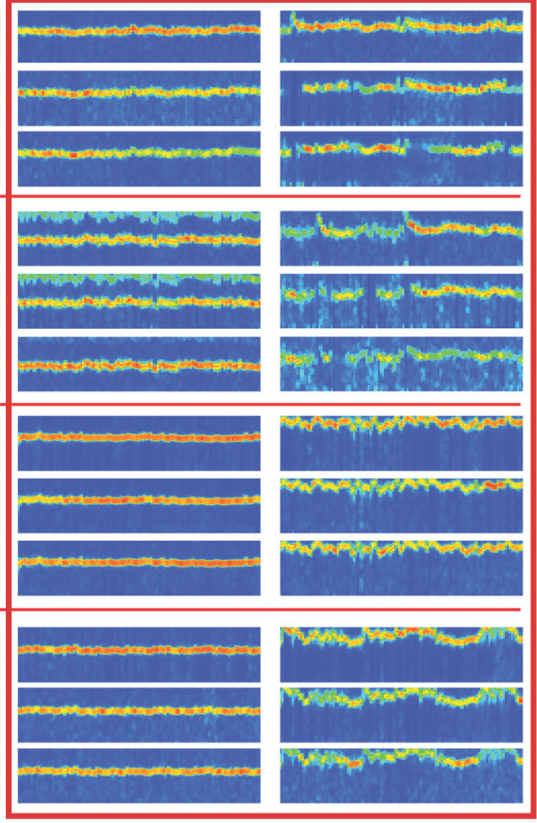

$27^{\circ} \mathrm{C}$

$31^{\circ} \mathrm{C}$

Figure 4. Spectrograms of activity in the PD, LP, and PY neurons as a function of temperature from cold-and warm-acclimated animals. Each spectrogram block spans 0 - $6 \mathrm{~Hz}$ on the $y$-axis and 300 s on the $x$-axis; the color is normalized to maximum power of each individual preparation. $A-E$, The spectrograms of network activity from the $P D, L P$, and $P Y$ neurons from cold-acclimated animals $\left(7^{\circ} \mathrm{C}\right)$ as a function of temperature from 15 to $31^{\circ} \mathrm{C} . \boldsymbol{F}-\mathbf{I}$, Spectrograms of network activity from warm-acclimated animals $\left(19^{\circ} \mathrm{C}\right.$ ) plotted as a function of temperature from 15 to $31^{\circ} \mathrm{C} .0$ nly temperatures recorded from 15 to $31^{\circ} \mathrm{C}$ are displayed for clarity. The missing spectrogram block $\left(E ; 31^{\circ} \mathrm{C}\right)$ is missing because that preparation crashed at $27^{\circ} \mathrm{C}$, and therefore the temperature was not raised further.

\section{Robustness of circuit performance}

The RI is a useful and intuitively appealing measurement but has unwieldy statistical properties. We therefore used a log-odds transform of the RI (LORI) (see Materials and Methods) to per- form statistical comparisons of robustness across preparations. Cold-acclimated preparations were highly robust at moderate acute temperatures, but their robustness tended to decrease above $23^{\circ} \mathrm{C}$ (Fig. $6 \mathrm{~A}$ ). Mid-acclimated animals also were robust at 


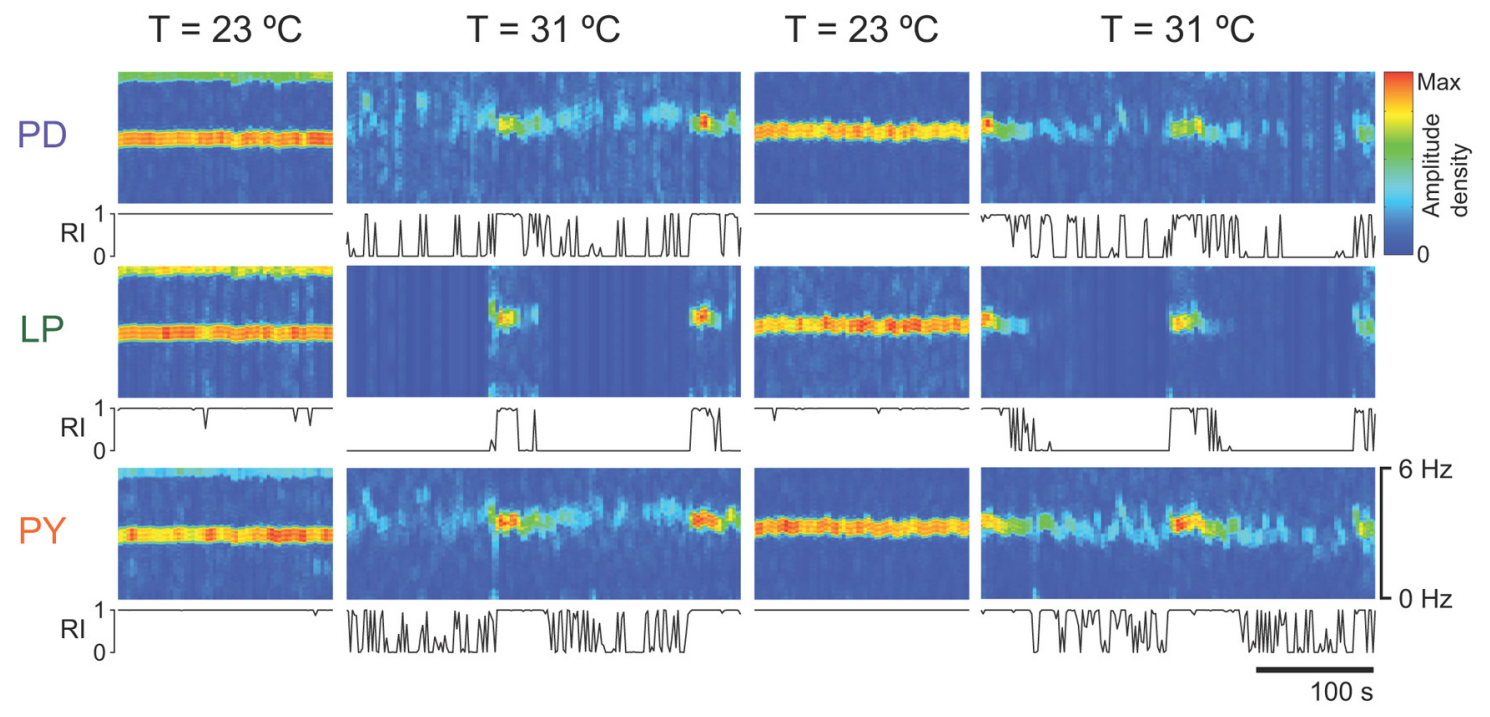

Figure 5. Reversibility, reproducibility, and quantification of crashes. Shown are spectrograms of PD, LP, and PY neuron activity over four sequential recordings, alternating between the same temperatures to show a crash and subsequent recovery. The color code in each spectrogram shows amplitude density, the square root of power density. Each spectrogram is individually normalized. Below each spectrogram, the RI (see Materials and Methods) of each neuron is plotted as a function of time.
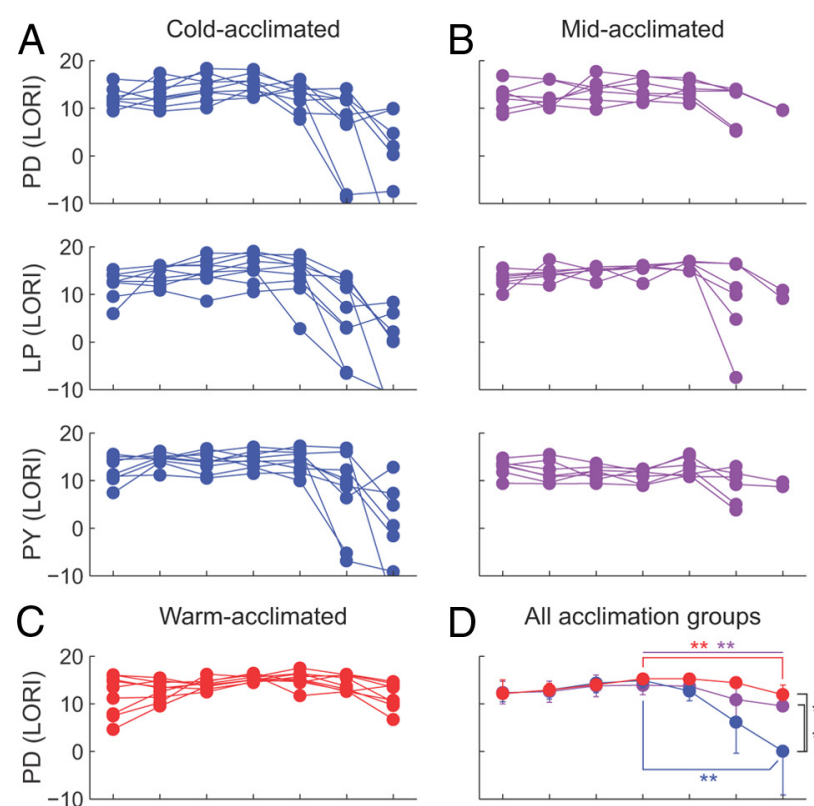

D
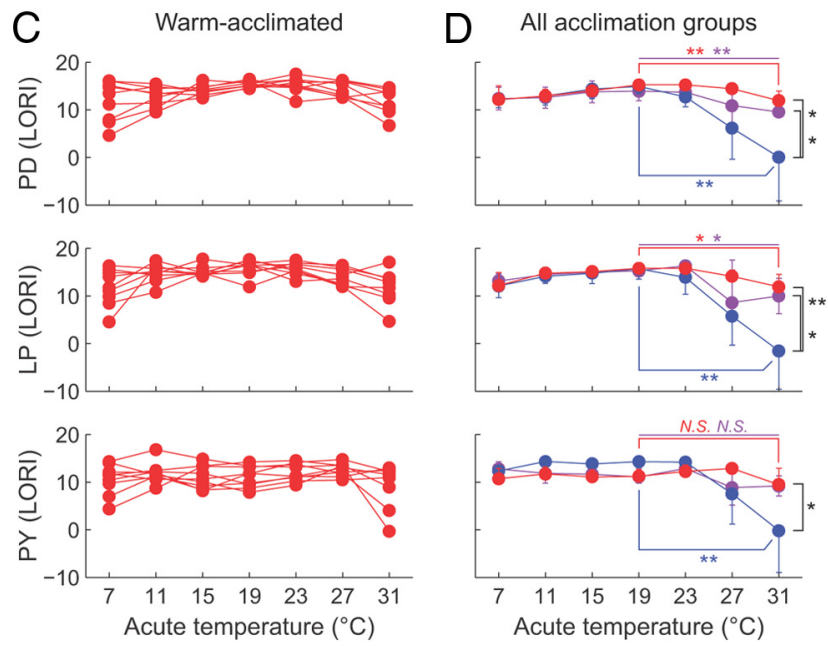

Figure 6. Cold-acclimated animals have less-robust pyloric rhythms at high acute temperatures. $\boldsymbol{A}$, Robustness, quantified by LORI (see Materials and Methods), at a range of acute temperatures, for cold-acclimated animals. Each line represents a single animal. $\boldsymbol{B}$, Similar to $A$, but for mid-acclimated animals. $\boldsymbol{C}$, Similar to $\boldsymbol{A}$ and $\boldsymbol{B}$, but for warm-acclimated animals. $\boldsymbol{D}$, Mean LORI for each acclimation group and acute temperature combination, plotted together. Error bars are $95 \%$ confidence intervals for the sample mean. Results of particularly important unpaired $t$ tests are illustrated. ${ }^{*} p<0.05 ;{ }^{* *} p<0.01 ;$ N.S., not significant. moderate temperatures but tended to stay more robust at high temperatures (Fig. 6B). Warm-acclimated animals showed an even stronger tendency to remain robust at high temperatures (Fig. 6C). For the PD neuron, we found significant effects of acute temperature $\left(p<10^{-4}\right)$ and acclimation group $(p<0.001)$, and a significant interaction between these treatments $\left(p<10^{-4}\right.$, two-way repeated-measures ANOVA). Furthermore, while all three acclimation groups showed a significant decline in robustness from 19 to $31^{\circ} \mathrm{C}$ ( $p<0.01$ for all three, unpaired $t$ test), the robustness at $31^{\circ} \mathrm{C}$ was significantly lower for the cold-acclimated group (Fig. $6 D$, top; $p<0.05$ for warm vs cold and mid vs cold, unpaired $t$ test). Similar results were obtained for the LP and PY neurons (Fig. $6 D$, middle and bottom). For the PY neuron, there was a nonsignificant main effect of acclimation group on robustness $(p=0.77)$, but there was still a significant interaction between acute temperature and acclimation group $\left(p<10^{-4}\right.$, two-way repeated-measures ANOVA). Additional statistical tests are summarized in Figure $6 D$.

\section{Animal-to-animal variability of rhythm dynamics}

Within acclimation groups, the variability in the phase of the pyloric neurons increased with temperature. The irregularity in the bursts of the three cells at a given temperature was quantified by measuring the coherence phase between each cell pair (PD-LP, LP-PY, PY-PD; Fig. 7). This generated two values for each cell pair at each temperature: a coherence magnitude (from 0 to 1 ) that captures how correlated activity in the two neurons is at the pyloric frequency, and a coherence phase that loosely captures the phase difference between the centers of the bursts of the neurons. Rhythms with high coherence are shown as dots closer to the outer rim of the unit circle. The higher the variability across animals at a certain temperature, the more the dots are spread out around the phase circle.

In the cold-acclimated group, the PD-LP and the LP-PY coherence showed a significant effect of acute temperature on variance ( $p<0.05$, Levene's $s$ test). In the warm-acclimated group, the LP-PY and PY-PD coherence also displayed a significant effect of acute temperature on variance ( $p<0.05$, Levene's $s$ test). The middle-acclimated group had no statistically significant change in coherence variability with temperature, yet irregularity in the phase and coherence can still be seen at various temperatures. 

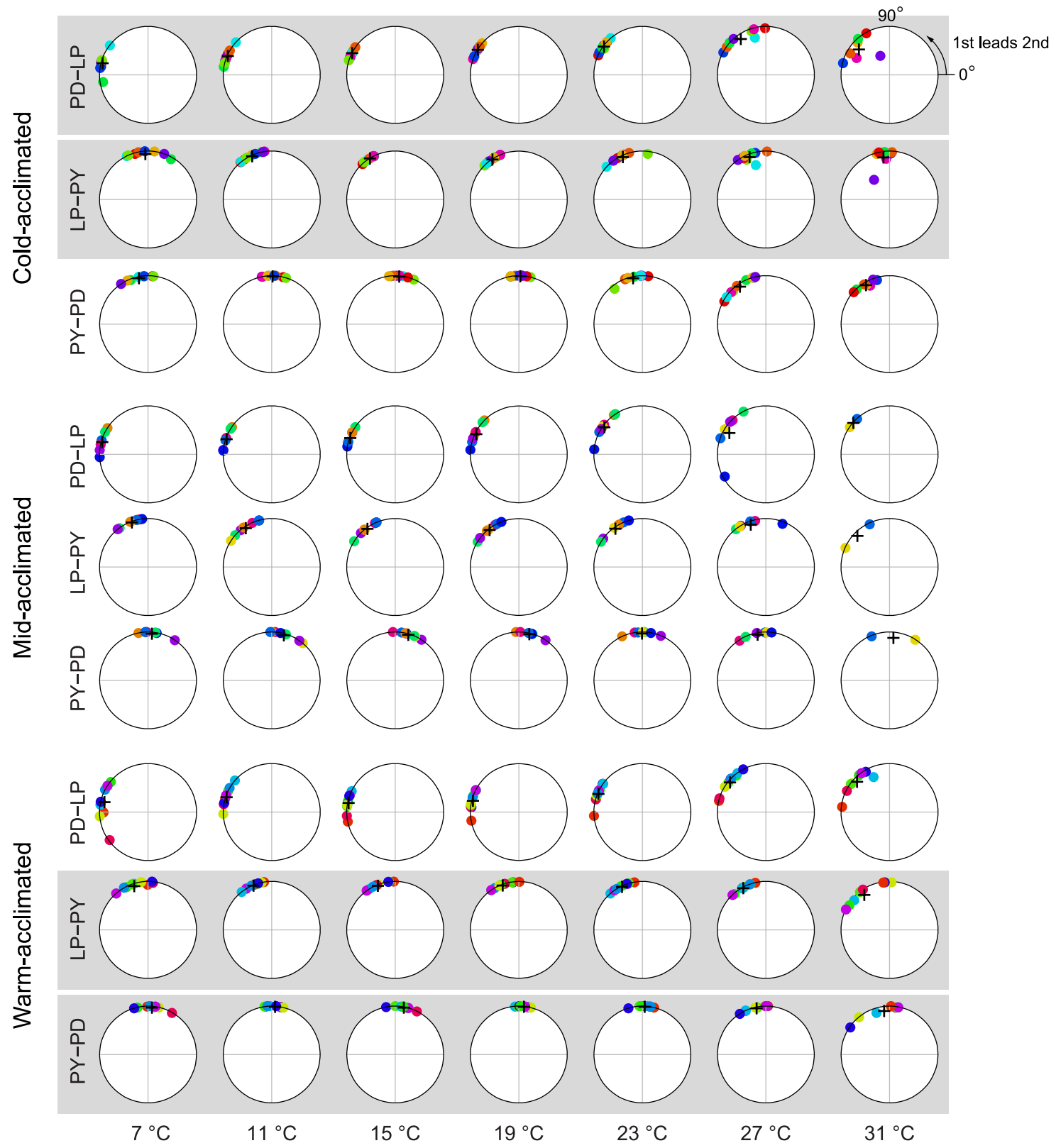

Figure 7. Phase coherence between pairs of pyloric neuron spike trains versus acute temperature, for preparations acclimated to different temperatures. The outer rim of each circle represents a coherence magnitude of 1 . The phase angle for each point captures the average distance in phase between the centers of two cell type bursts. The phase is plotted, as the first cell type leading the second, going counterclockwise starting at the right-most point on the circle. Each color represents a different preparation. The black crosses represent the mean coherence phase within each group. The rows with gray backdrop displayed significantly different variance across acute temperature ( $p<0.05$, Levene's s test) (see Materials and Methods).

\section{Discussion}

In this work, we used acute and long-term temperature modifications to determine the extent to which individual animals responded in a stereotyped fashion to a global environmental perturbation. Considerable evidence now argues that individual animals vary considerably in the parameters that govern network performance, although they can produce reliable behaviors (Golowasch et al., 1999b, 2002; Goldman et al., 2001; Prinz et al., 2004; Schulz et al., 2006, 2007; Tobin and Calabrese, 2006; Norris et al., 2007, 2011; Goaillard et al., 2009; Taylor et al., 2009; Tobin et al., 2009; Prinz, 2010; Roffman et al., 2012). Although multiple solutions can be consistent with "good enough" performance (Marder and Goaillard, 2006; Marder, 2011; Marder and Taylor, 2011), most individuals in the population must nevertheless respond robustly to the environmental perturbations that they typ- ically encounter. The crabs used in this study, C. borealis, live in the Atlantic Ocean and routinely encounter substantial temperature fluctuations, so these experiments are essentially probing the extent to which these animals can deal with one of the most salient challenges of their natural environment.

We were surprised to discover that acclimation of animals to different temperatures did not change the frequency and phase relationships of the pyloric rhythms measured at any given temperature, especially so because temperature acclimation of the lobster, Homarus americanus, resulted in shifts in the frequencytemperature relationship of the heart rate (Camacho et al., 2006). Because the frequency of the pyloric rhythm at $19^{\circ} \mathrm{C}$ is more than twice as fast as at $7^{\circ} \mathrm{C}$ (Tang et al., 2010), we predicted that acclimation would shift the temperature-frequency relationship of the pyloric rhythm. This expectation was not unreasonable based 
on evidence from a number of studies showing that neurons homeostatically adjust their firing rates, either through intrinsic or synaptic mechanisms (or both), in response to chronic increases or decreases in neuronal activity (Thoby-Brisson and Simmers, 1998, 2000, 2002; Desai et al., 1999; Pratt et al., 2003; Pratt and Aizenman, 2007). That acclimation did not cause such a shift suggests that the pyloric network frequency may not be a crucial controlled variable for homeostatic regulation, although it is often (and sometimes implicitly) assumed that the set point is related in a simple manner to frequency (LeMasson et al., 1993; Liu et al., 1998; Golowasch et al., 1999a). When the descending modulatory inputs to the STG are removed, the pyloric rhythm usually stops, but recovers over the next several days, but at a lower frequency (Thoby-Brisson and Simmers, 1998; Golowasch et al., 1999a). Thus, we now speculate that the alternating triphasic pattern of the pyloric rhythm, rather than its frequency, could be the target of homeostatic regulation.

All of the animals in this study were acclimated for at least 3 weeks. Previous work in crustaceans, on numerous physiological processes, showed that most regulatory processes come to steady state after 2 weeks of acclimation (Zecević and Levitan, 1980; Lagerspetz, 1994; Camacho et al., 2006). Some crabs were acclimated for as long as 6 weeks, and preparations from these animals gave data consistent with those from the 3-week-acclimated animals. Therefore, it appears that the 3 week acclimation times we used were sufficient to produce whatever acclimation-induced changes were likely to occur.

While the pyloric rhythm is very robust over a wide temperature range, "crashes"-periods of time during which the pyloric rhythms were disrupted-were apparent when the temperature was increased to values higher than crabs routinely experience. Because the rate of each enzymatic or ion channel process increases exponentially with temperature, even slightly different temperature dependencies between two compensatory cellular processes will cause the rates of those processes to become unmatched at extreme temperatures. It then follows that, as temperature is increased to the point where the cellular processes are no longer adequately matched to each other, circuit performance can be expected to degrade, perhaps catastrophically, resulting in a crash.

Nevertheless, if all pyloric circuits had similar parameters, one would expect all of them to crash in more-or-less the same way. But if pyloric circuit parameters differ markedly across individuals, as previous data argue (Golowasch et al., 1999b; Marder and Goaillard, 2006; Schulz et al., 2006, 2007; Goaillard et al., 2009), one would expect preparations from different animals to crash in different ways. Thus, degraded circuit performance at extreme temperatures provides a way to distinguish whether the underlying parameters of individual pyloric circuits are diverse, or are highly constrained.

Qualitatively, we found that individual circuits crashed at different temperatures, to different extents, and/or in different ways at extreme temperatures (Figs. 4, 7). In general, these results are consistent with the notion that the circuits from individual animals are composed of different sets of underlying parameters that confer good enough solutions (Prinz et al., 2004; Marder and Goaillard, 2006; Marder, 2011). Thus, these data provide experimental validation for this theoretical notion at the circuit level.

Quantitatively, while temperature acclimation did not induce changes in network frequency or phase relationships, it did produce alterations in the robustness of circuit performance at extreme temperatures. In response to acute increases in temperature, disruption of circuit performance occurred at lower tem- peratures in cold-acclimated animals than in warm-acclimated animals (qualitatively, Fig. 4; quantitatively, Fig. 6). We interpret these results as a shift in the operational regime of good enough solutions for appropriate network behavior. We suggest that acclimation induces an alteration in underlying conductance parameters and moves the circuit toward the "center" of good enough solutions and thus further from the boundary between good enough solutions and crashed solutions. Importantly, this alteration of parameters must occur in such a way as to maintain robust and consistent circuit performance in the permissive temperature range.

The observation that acclimation shifts the operational range of circuit performance is consistent with long-known behavioral experiments in locomotion performance of fish (Robertson and Money, 2012) and more recent results in the lobster heart (Worden et al., 2006). In the case of the $H$. americanus heart, warm acclimation shifted the upper limit for cardiac function from 24 to $29^{\circ} \mathrm{C}$ (Worden et al., 2006). The results reported in this paper are particularly intriguing because acclimation shifted the limits of robust network performance without changing its behavior over the permissive temperature range.

Increasing evidence suggests that variability in underlying system components is a basic feature of all organisms, including Escherichia coli and yeast (Elowitz et al., 2002; Korobkova et al., 2004; Stolovicki et al., 2006; Emonet and Cluzel, 2008; Eldar and Elowitz, 2010; Dufour et al., 2011; Stolovicki and Braun, 2011; Sneddon et al., 2012), where variability in gene expression and in the concentrations of molecular constituents are thought to allow cells to explore parameter space and to respond appropriately to changing external conditions.

In complex nervous systems, variability can be an important contributor to system performance and robustness (Padmanabhan and Urban, 2010). For example, in songbirds, there is a neural circuit that generates variability in vocal performance (Kao et al., 2008). This variability is important for motor exploration and vocal plasticity and also for enabling animals to respond to changing external conditions such as social context (Stepanek and Doupe, 2010).

In summary, these experiments demonstrate that, although individual animals can differ considerably in the number of ion channels and receptors expressed in a circuit important for survival, they can nonetheless show robust and stereotyped responses to a physiologically relevant environmental perturbation. Nonetheless, more extreme perturbations reveal the essential differences between animals, demonstrating that some members of the population will be more successful than others in responding to extreme environmental conditions. Thus, the variability among individuals in the population may be useful for allowing the species to be successful under different kinds of environmental stresses.

\section{References}

Camacho J, Qadri SA, Wang H, Worden MK (2006) Temperature acclimation alters cardiac performance in the lobster Homarus americanus. J Comp Physiol A Neuroethol Sens Neural Behav Physiol 192:1327-1334.

Cossins AR, Bowler K (1987) Temperature biology of animals. London: Chapman and Hall.

Dehghani M, Xiao C, Money TG, Shoemaker KL, Robertson RM (2011) Protein expression following heat shock in the nervous system of Locusta migratoria. J Insect Physiol 57:1480-1488.

Desai NS, Rutherford LC, Turrigiano GG (1999) Plasticity in the intrinsic excitability of cortical pyramidal neurons. Nat Neurosci 2:515-520.

Dillon ME, Wang G, Garrity PA, Huey RB (2009) Review: thermal preference in Drosophila. J Therm Biol 34:109-119.

Donahue MJ, Nichols A, Santamaria CA, League-Pike PE, Krediet CJ, Perez 
KO, Shulman MJ (2009) Predation risk, prey abundance, and the vertical distribution of three brachyuran crabs on Gulf of Maine shores. J Crustacean Biol 29:523-531.

Dufour YS, Sneddon MW, Emonet T (2011) Thermal robustness: lessons from bacterial chemotaxis. Curr Biol 21:R465-R468.

Eldar A, Elowitz MB (2010) Functional roles for noise in genetic circuits. Nature 467:167-173.

Elowitz MB, Levine AJ, Siggia ED, Swain PS (2002) Stochastic gene expression in a single cell. Science 297:1183-1186.

Emonet T, Cluzel P (2008) Relationship between cellular response and behavioral variability in bacterial chemotaxis. Proc Natl Acad Sci U S A 105:3304-3309.

Garrity PA, Goodman MB, Samuel AD, Sengupta P (2010) Running hot and cold: behavioral strategies, neural circuits, and the molecular machinery for thermotaxis in C. elegans and Drosophila. Genes Dev 24:2365-2382.

Goaillard JM, Taylor AL, Schulz DJ, Marder E (2009) Functional consequences of animal-to-animal variation in circuit parameters. Nat Neurosci 12:1424-1430.

Goldman MS, Golowasch J, Marder E, Abbott LF (2001) Global structure, robustness, and modulation of neuronal models. J Neurosci 21:52295238.

Golowasch J, Casey M, Abbott LF, Marder E (1999a) Network stability from activity-dependent regulation of neuronal conductances. Neural Comput 11:1079-1096.

Golowasch J, Abbott LF, Marder E (1999b) Activity-dependent regulation of potassium currents in an identified neuron of the stomatogastric ganglion of the crab Cancer borealis. J Neurosci 19:RC33(1-5).

Golowasch J, Goldman MS, Abbott LF, Marder E (2002) Failure of averaging in the construction of a conductance-based neuron model. J Neurophysiol 87:1129-1131.

Grashow R, Brookings T, Marder E (2009) Reliable neuromodulation from circuits with variable underlying structure. Proc Natl Acad Sci U S A 106:11742-11746.

Hille B (2001) Ion channels of excitable membranes, Ed 3. Sunderland, MA: Sinauer.

Johnson BR, Peck JH, Harris-Warrick RM (1991) Temperature sensitivity of graded synaptic transmission in the lobster stomatogastric ganglion. J Exp Biol 156:267-285.

Kao MH, Wright BD, Doupe AJ (2008) Neurons in a forebrain nucleus required for vocal plasticity rapidly switch between precise firing and variable bursting depending on social context. J Neurosci 28:1323213247.

Korobkova E, Emonet T, Vilar JM, Shimizu TS, Cluzel P (2004) From molecular noise to behavioural variability in a single bacterium. Nature 428:574-578.

Lagerspetz A (1994) Thermal acclimation, neuromuscular synaptic delay and miniature end-plate current decay in the frog Rana temporaria. J Exp Biol 187:131-142.

LeMasson G, Marder E, Abbott LF (1993) Activity-dependent regulation of conductances in model neurons. Science 259:1915-1917.

Lenz PH, Hower AE, Hartline DK (2005) Temperature compensation in the escape response of a marine copepod, Calanus finmarchicus (Crustacea). Biol Bull 209:75-85.

Levene H (1960) Robust tests for the equality of variance. In: Contributions to probability and statistics, pp 278-292. Palo Alto, CA: Stanford UP.

Liu Z, Golowasch J, Marder E, Abbott LF (1998) A model neuron with activity-dependent conductances regulated by multiple calcium sensors. J Neurosci 18:2309-2320.

Luther JA, Robie AA, Yarotsky J, Reina C, Marder E, Golowasch J (2003) Episodic bouts of activity accompany recovery of rhythmic output by a neuromodulator- and activity-deprived adult neural network. J Neurophysiol 90:2720-2730.

Marder E (2011) Variability, compensation, and modulation in neurons and circuits. Proc Natl Acad Sci U S A 108 [Suppl 3]:15542-15548.

Marder E, Bucher D (2007) Understanding circuit dynamics using the stomatogastric nervous system of lobsters and crabs. Annu Rev Physiol 69:291-316.

Marder E, Goaillard JM (2006) Variability, compensation and homeostasis in neuron and network function. Nat Rev Neurosci 7:563-574.

Marder E, Taylor AL (2011) Multiple models to capture the variability in biological neurons and networks. Nat Neurosci 14:133-138.
Miller RG, Brown BW (1997) Beyond ANOVA: basics of applied statistics. New York: Chapman and Hall/CRC.

Neumeister H, Ripley B, Preuss T, Gilly WF (2000) Effects of temperature on escape jetting in the squid Loligo opalescens. J Exp Biol 203:547-557.

Norris BJ, Weaver AL, Wenning A, García PS, Calabrese RL (2007) A central pattern generator producing alternative outputs: pattern, strength, and dynamics of premotor synaptic input to leech heart motor neurons. J Neurophysiol 98:2992-3005.

Norris BJ, Wenning A, Wright TM, Calabrese RL (2011) Constancy and variability in the output of a central pattern generator. J Neurosci 31:4663-4674.

Padmanabhan K, Urban NN (2010) Intrinsic biophysical diversity decorrelates neuronal firing while increasing information content. Nat Neurosci 13:1276-1282.

Percival D, Walden A (1993) Spectral analysis for physical applications, multitaper and conventional univariate techniques. New York: Cambridge UP.

Pratt KG, Aizenman CD (2007) Homeostatic regulation of intrinsic excitability and synaptic transmission in a developing visual circuit. J Neurosci 27:8268-8277.

Pratt KG, Watt AJ, Griffith LC, Nelson SB, Turrigiano GG (2003) Activitydependent remodeling of presynaptic inputs by postsynaptic expression of activated CaMKII. Neuron 39:269-281.

Prinz AA (2010) Computational approaches to neuronal network analysis. Philos Trans R Soc Lond B Biol Sci 365:2397-2405.

Prinz AA, Bucher D, Marder E (2004) Similar network activity from disparate circuit parameters. Nat Neurosci 7:1345-1352.

Rehm KJ, Taylor AL, Pulver SR, Marder E (2008) Spectral analyses reveal the presence of adult-like activity in the embryonic stomatogastric motor patterns of the lobster, Homarus americanus. J Neurophysiol 99:31043122.

Robertson RM (1993) Effects of temperature on synaptic potentials in the locust flight system. J Neurophysiol 70:2197-2204.

Robertson RM, Money TGA (2012) Temperature and neuronal circuit function: compensation, tuning and tolerance. Curr Opin Neurobiol. Advance online publication. Retrieved June 14, 2012. doi: 10.1016/j.conb.2012.01.008.

Robertson RM, Xu H, Shoemaker KL, Dawson-Scully K (1996) Exposure to heat shock affects thermosensitivity of the locust flight system. J Neurobiol 29:367-383.

Roffman RC, Norris BJ, Calabrese RL (2012) Animal-to-animal variability of connection strength in the leech heartbeat central pattern generator. J Neurophysiol 107:1681-1693.

Schulz DJ, Goaillard JM, Marder E (2006) Variable channel expression in identified single and electrically coupled neurons in different animals. Nat Neurosci 9:356-362.

Schulz DJ, Goaillard JM, Marder EE (2007) Quantitative expression profiling of identified neurons reveals cell-specific constraints on highly variable levels of gene expression. Proc Natl Acad Sci U S A 104:13187-13191.

Seeger HM, Aldrovandi L, Alessandrini A, Facci P (2010) Changes in single $\mathrm{K}^{+}$channel behavior induced by a lipid phase transition. Biophys $\mathrm{J}$ 99:3675-3683.

Shoemaker KR, Fairman R, Schultz DA, Robertson AD, York EJ, Stewart JM, Baldwin RL (1990) Side-chain interactions in the C-peptide helix: Phe 8 ... His 12+. Biopolymers 29:1-11.

Sneddon MW, Pontius W, Emonet T (2012) Stochastic coordination of multiple actuators reduces latency and improves chemotactic response in bacteria. Proc Natl Acad Sci U S A 109:805-810.

Stepanek L, Doupe AJ (2010) Activity in a cortical-basal ganglia circuit for song is required for social context-dependent vocal variability. J Neurophysiol 104:2474-2486.

Stolovicki E, Braun E (2011) Collective dynamics of gene expression in cell populations. PLoS One 6:e20530.

Stolovicki E, Dror T, Brenner N, Braun E (2006) Synthetic gene recruitment reveals adaptive reprogramming of gene regulation in yeast. Genetics 173:75-85.

Szabo TM, Brookings T, Preuss T, Faber DS (2008) Effects of temperature acclimation on a central neural circuit and its behavioral output. J Neurophysiol 100:2997-3008.

Tang LS, Goeritz ML, Caplan JS, Taylor AL, Fisek M, Marder E (2010) Precise temperature compensation of phase in a rhythmic motor pattern. PLoS Biol 8:e1000469. 
Taylor AL, Goaillard JM, Marder E (2009) How multiple conductances determine electrophysiological properties in a multicompartment model. J Neurosci 29:5573-5586.

Thoby-Brisson M, Simmers J (1998) Neuromodulatory inputs maintain expression of a lobster motor pattern-generating network in a modulation-dependent state: evidence from long-term decentralization in vitro. J Neurosci 18:2212-2225.

Thoby-Brisson M, Simmers J (2000) Transition to endogenous bursting after long-term decentralization requires de novo transcription in a critical time window. J Neurophysiol 84:596-599.

Thoby-Brisson M, Simmers J (2002) Long-term neuromodulatory regulation of a motor pattern-generating network: maintenance of synaptic efficacy and oscillatory properties. J Neurophysiol 88:2942-2953.

Thomson D, Chave A (1991) Jackknifed error estimates for spectra, coher- ences, and transfer functions. In: Advances in spectrum analysis and array processing, pp 58-113. Englewood Cliffs, NJ: Prentice-Hall.

Tobin AE, Calabrese RL (2006) Endogenous and half-center bursting in morphologically inspired models of leech heart interneurons. J Neurophysiol 96:2089-2106.

Tobin AE, Cruz-Bermúdez ND, Marder E, Schulz DJ (2009) Correlations in ion channel mRNA in rhythmically active neurons. PLoS One 4:e6742.

Worden MK, Clark CM, Conaway M, Qadri SA (2006) Temperature dependence of cardiac performance in the lobster Homarus americanus. J Exp Biol 209:1024-1034.

Zecević D, Levitan H (1980) Temperature acclimation: effects on membrane physiology of an identified snail neuron. Am J Physiol 239:C47-C57.

Zhurov Y, Brezina V (2005) Temperature compensation of neuromuscular modulation in Aplysia. J Neurophysiol 94:3259-3277. 